\title{
Comparison of long-term outcomes of colonic stenting as a "bridge to surgery" and emergency surgery in patients with left-sided malignant colonic obstruction
}

\author{
Supakij Khomvilai, Sukit Pattarajierapan \\ Surgical Endoscopy Colorectal Division, Department of Surgery, Faculty of Medicine, Chulalongkorn University, Bangkok, Thailand
}

Purpose: Long-term oncologic outcomes of colonic stenting as a "bridge to surgery" in patients with left-sided malignant colonic obstruction (LMCO) are unclear. This study was performed to compare long-term outcomes of self-expandable metal stent (SEMS) insertion as a bridge to surgery and emergency surgery in patients with acute LMCO.

Methods: This retrospective cohort study included patients with acute LMCO who underwent SEMS insertion as a bridge to surgery or emergency surgery. The primary outcomes were 5-year disease-free survival (DFS), overall survival (OS), and recurrence rate. Survival outcomes were determined using the Kaplan-Meier method and compared using log-rank tests.

Results: There was a trend of worsening 5-year OS rate in the SEMS group compared with emergency surgery group (45\% vs. $57 \%, \mathrm{P}=0.07$ ). In stage-wise subgroup analyses, a trend of deteriorating 5 -year OS rate in the SEMS group with stage III ( $43 \%$ vs. $59 \%, \mathrm{P}=0.06)$ was observed. The 5 -year DFS and recurrence rate were not different between groups. The overall median follow-up time was 58 months. On multivariate analysis, age of $\geq 65$ years and American Joint Committee on Cancer stage of $\geq \mathrm{III}$, and synchronous metastasis were significant poor prognostic factors for OS (hazard ratio [HR], 1.709; 95\% confidence interval $[\mathrm{CI}], 1.007-2.900 ; \mathrm{P}=0.05 / \mathrm{HR}, 1.988 ; 95 \% \mathrm{CI}, 1.038-3.809 ; \mathrm{P}=0.04 / \mathrm{HR}, 2.146 ; 95 \% \mathrm{CI}$, 1.191-3.866; $\mathrm{P}=0.01$; respectively).

Conclusion: SEMS as a bridge to surgery may have adverse oncologic outcomes. Patients in the SEMS group had a trend of worsening 5-year OS rate without higher recurrence.

Keywords: Colon cancer; Intestinal obstruction; Emergency treatment; Colorectal surgery; Self expandable metal stent

\section{INTRODUCTION}

Colorectal cancer (CRC) is the third most common malignant disease worldwide, with more than 1.8 million new cases and 881,000 deaths in 2018 [1]. It has been estimated that $7 \%$ to $29 \%$ of patients with CRC present with colonic obstruction [2]. The

Received: Apr 1, 2021 - Revised: May 20, 2021 - Accepted: May 26, 2021 Correspondence to: Supakij Khomvilai, MD

Surgical Endoscopy Colorectal Division, Department of Surgery, Faculty of Medicine, Chulalongkorn University, 1873 Rama IV Rd, Pathumwan,

Bangkok 10330, Thailand

Email:Supakij.k@chulahospital.org

ORCID: https://orcid.org/0000-0002-9703-9627

(C) 2023 The Korean Society of Coloproctology

This is an open-access article distributed under the terms of the Creative Commons Attribution NonCommercial License (https://creativecommons.org/licenses/by-nc/4.0) which permits unrestricted non-

commercial use, distribution, and reproduction in any medium, provided the original work is properly cited. clinical outcomes after resection of patients who present with colonic obstruction are worse than those of patients who present without obstruction. The mortality rate was higher in patients with obstructed CRC than in those without obstruction (17\% vs. $6 \%$, respectively) [3].

There is ongoing debate on the optimal approach to the treatment of patients with left-sided malignant colonic obstruction (LMCO). The mortality and morbidity rates for emergency surgery are $15 \%$ to $20 \%$ and $45 \%$ to $50 \%$, respectively, as opposed to a mortality rate of $0.9 \%$ to $6 \%$ for elective surgery $[4,5]$. The reasons for the high morbidity and mortality of emergency surgery are advanced stage of neoplasm, electrolyte imbalances, malnutrition, friable mucosa due to distention, and fecal loading of the unprepared colon [6].

The concept of self-expandable metal stent (SEMS) insertion as a "bridge to surgery," which converts an emergency situation to an 
elective one, is appealing. Besides colonic decompression, SEMS insertion allows for preoperative bowel preparation and makes elective single-stage colonic resection possible with decreased risk of permanent stoma creation. In previous randomized controlled trials, SEMS insertion showed favorable short-term outcomes with lower morbidity and permanent stoma rates [7-11].

However, the long-term oncologic outcomes in patients with curable diseases are unclear. Shear forces induced by the SEMS could lead to dissemination of cancer cells into the peritoneal cavity, lymphatic fluid, and bloodstream [12, 13]. A few studies reported poor oncologic outcomes in patients who underwent SEMS insertion, especially in those with SEMS-related perforation $[14,15]$. A Japanese nationwide study also reported significantly poorer overall survival (OS) rates in patients who underwent SEMS as a bridge to surgery than emergency surgery [16]. In contrast, many studies reported high success rates and comparable oncologic outcomes for SEMS insertion [17-23].

Because of these inconsistent findings, additional research is needed on SEMS insertion as a bridge to surgery in patients with LMCO. This study aimed to compare long-term oncologic and perioperative outcomes of SEMS insertion as a bridge to surgery and emergency surgery in patients with curable LMCO.

\section{METHODS}

\section{Study design and population}

We conducted a single-center retrospective study using a prospectively maintained endoscopy database of patients with acute LMCO. We included all patients who underwent surgical resection with curative intent on an intention-to-treat basis at King Chulalongkorn Memorial Hospital between January 2008 and December 2014. LMCO was defined as the presence of at least 1 obstructive symptom (distended abdomen, obstipation, nausea/ vomiting) and radiological (dilated colon proximal to the tumor) or endoscopic findings of malignant colonic obstruction between the splenic flexure and rectosigmoid junction. The tumor location of the enrolled patients was defined with abdominal computed tomographic scan by the radiologists. Patients who underwent an intervention with palliative intent or had signs of peritonitis or perforation, colonic ischemia, previous colonic stenting, or contraindication to endoscopic treatment were excluded. The on-call consultant colorectal surgeon decided whether to perform SEMS insertion as a bridge to surgery or surgical intervention after discussion with the patients. The main factors in decision making were the patient's financial status and medical reimbursement. In Thailand, SEMS insertion has been covered for reimbursement only in patients with the Civil Servant Medical Benefit Scheme. Patients with other medical benefit schemes must pay 1,000 US dollars for a SEMS if they undergo colonic stenting.

The study protocol was approved by the Institutional Review Board of Chulalongkorn University (No. 197-63). Due to the retrospective design of the study, the requirement for consent was waived by the ethics committee.

\section{SEMS insertion technique}

All procedures were performed in the operation theatre under conscious sedation. We inserted the SEMS under fluoroscopyguided direct endoscopic visualization. We did not dilate the stricture site before SEMS insertion. Following colonoscopic assessment of the obstructed site, a 0.89 -mm soft-tipped hydrophilic Jagwire (Boston Scientific) was passed through the strictured lumen under fluoroscopic guidance. We did not use enteral contrast to calculate the length of the SEMS. At our center, we only use uncovered colonic stents of 1 size, i.e., $120 \mathrm{~mm}$ in length and $24 \mathrm{~mm}$ in diameter (Niti-S D-type, Taewoong Medical Corp). We assessed the obstructed lesion preoperatively using computed tomography to ensure that a SEMS that was $120 \mathrm{~mm}$ in length would be adequate. During deployment, we focused on the distal end of the stent that was placed $30 \mathrm{~mm}$ distal to the tumor and monitored the shape of the proximal end of the stent using fluoroscopy. The distance from the tumor to the distal end of the stent decreased to $20 \mathrm{~mm}$ after complete deployment due to foreshortening of the SEMS. After successful SEMS insertion, we attempted to perform colonic resection within 2 weeks as recommended. The surgery performed after SEMS insertion was determined by the consultant colorectal surgeons.

\section{Surgical intervention for left-sided malignant colonic obstruction}

Patients undergoing emergency surgery were operated on as soon as possible after initial stabilization. Surgical options included laparoscopic or open resection, subtotal/total colectomy, and segmental resection with or without on-table colonic lavage. Primary anastomosis and stoma formation were at the discretion of the consultant colorectal surgeons.

\section{Outcomes and definitions}

The primary outcomes of this study were long-term oncologic outcomes, including disease-free survival (DFS) and OS, and recurrence rate in the SEMS and emergency surgery groups.

DFS was defined as the interval from the date of surgery to cancer recurrence, death, or the last follow-up. OS was defined as the interval from the date of surgery to death or the last follow-up. Recurrence was defined as the development of any new malignant lesion within (locoregional recurrence) or outside (distant recurrence) the field of surgery after curative-intent resection.

The secondary outcomes were perioperative outcomes, including morbidity and mortality, technical and clinical success rates of SEMS insertion, temporary and permanent stoma rates, primary anastomosis rate, adjuvant chemotherapy access rate, and length of hospital stay. Postoperative complications were categorized using the Clavien-Dindo classification [24].

Technical success was defined as successful stent deployment with fluoroscopic confirmation. Clinical success was defined as 
resolution of obstructive symptoms with stool/flatus passage and oral diet tolerance.

\section{Statistical analysis}

Data were analyzed using Stata ver. 15.1 (Stata Corp). The distribution of the data was determined using the De Agostino-Pearson omnibus normality test. Normally distributed data were presented as means and standard deviations, and nonparametric data were presented as medians and interquartile ranges (IQR). Continuous variables were compared using 2-tailed Student t-tests, and categorical variables were compared using the 2-tailed chisquare tests or Fisher exact test, as appropriate. Survival outcomes were determined using the Kaplan-Meier method and compared using log-rank tests. Prognostic factors for OS were assessed using univariate and multivariate Cox proportional hazard models. All analyses were conducted based on the intention-to-treat principle. A P-value of $<0.05$ was considered to be statistically significant.

\section{RESULTS}

Between January 2008 and December 2014, 126 patients who underwent curative-intent surgery for LMCO fulfilled the eligibility criteria. Of them, 49 underwent SEMS insertion as a bridge to surgery, and 77 underwent emergency surgery (Fig. 1).

\section{Patient characteristics}

Table 1 shows the baseline characteristics of all 126 patients. The patients in the SEMS group were older than those in the emer- gency surgery group (mean age, 68 years vs. 61 years; $\mathrm{P}=0.01$ ). There were no significant between-group differences in sex, American Society of Anesthesiologists physical status classification, tumor stage, tumor location, follow-up time, and adjuvant chemotherapy access rate. However, patients in the SEMS group were more likely to receive the oxaliplatin-based chemotherapy with or without antiangiogenic drug $(\mathrm{P}=0.03)$. The median follow-up time for all patients was 58 months (IQR, 23-94 months).

\section{Primary outcomes}

Patients who developed perforation or clinical failure after SEMS insertion were included in the SEMS group for the intent-to-treat analyses. There was a trend of worsening 5-year OS rate in SEMS group compared with emergency surgery group (45\% vs. $57 \%$, $\mathrm{P}=0.07)$. In stage-wise subgroup analyses, 5-year OS rates were not significantly different for stage II and IV (stage II: $83 \%$ vs. $68 \%, \mathrm{P}=0.39$; stage IV: $19 \%$ vs. $38 \%, \mathrm{P}=0.29$; Figs. 2 , 3). However, a trend of deteriorating 5 -year OS rate in the SEMS group with stage III was observed ( $43 \%$ vs. $59 \%, \mathrm{P}=0.06$; Fig. 4). Fiveyear DFS rates were not significantly different in the SEMS and emergency surgery groups (stage II: $83 \%$ vs. $61 \%, \mathrm{P}=0.27$; stage III: $38 \%$ vs. $38 \%, \mathrm{P}=0.27$; Figs. 5,6 ).

Table 2 shows the rate and pattern of recurrence in both groups. There was no difference in the rate or site of recurrence between the SEMS and emergency surgery groups $(\mathrm{P}=0.71)$ for all patients. In the subgroup analysis of patients without metastases at the time of diagnosis, no differences in the rate and pattern of recurrence were observed $(\mathrm{P}=0.82)$.

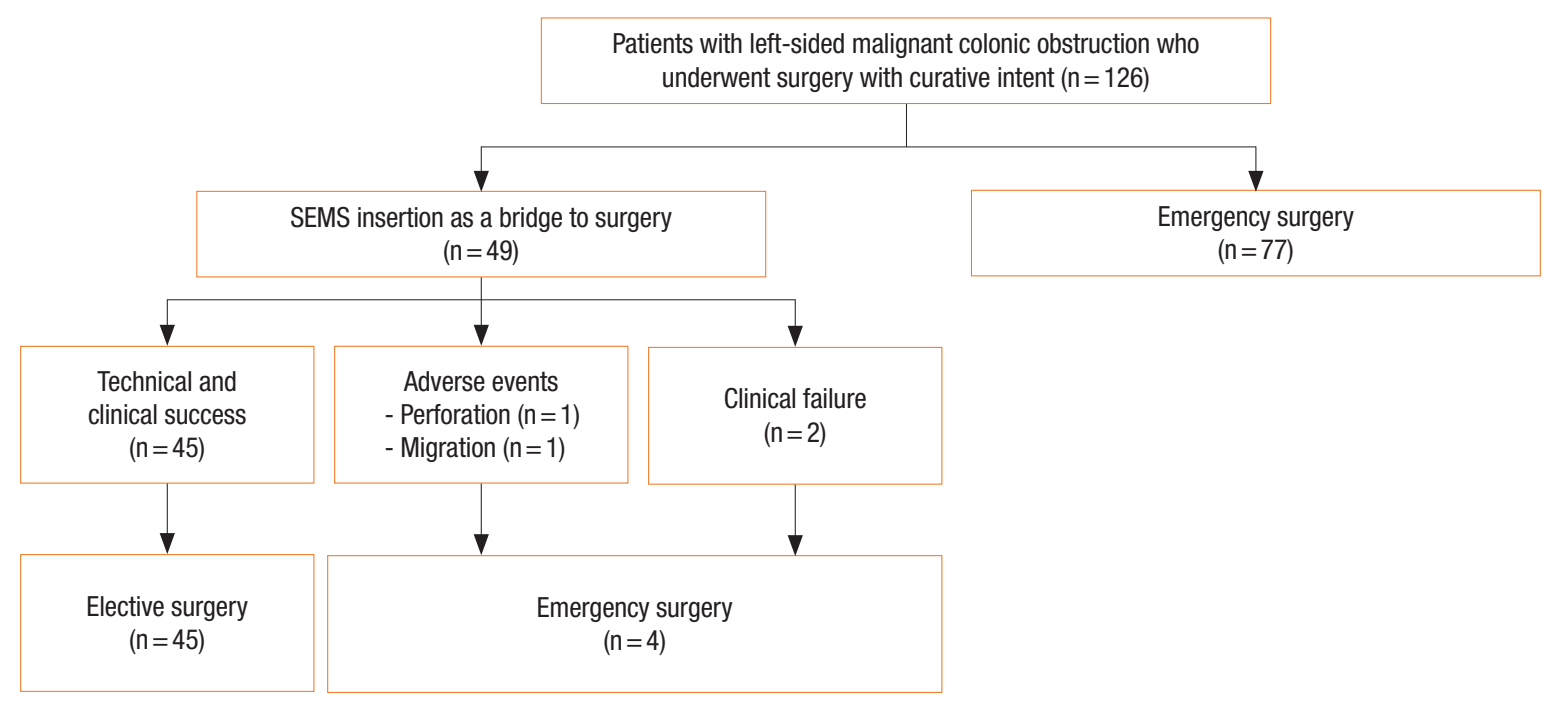

SEMS group on an intention-to-treat basis

Emergency surgery group $(n=49)$ $(n=77)$

Fig. 1. Flow chart of enrollment of patients with left-sided malignant obstruction who underwent surgery with curative intent. SEMS, self-expandable metal stent. 
Table 1. Baseline characteristics of the participants

\begin{tabular}{|c|c|c|c|}
\hline Characteristic & SEMS group & Emergency surgery group & P-value \\
\hline No. of participants & 49 & 77 & \\
\hline Age (yr) & $68 \pm 11.5$ & $61 \pm 14.3$ & $0.006^{*}$ \\
\hline Sex & & & 0.999 \\
\hline Male & $32(65.3)$ & $49(63.6)$ & \\
\hline Female & $17(34.7)$ & $28(36.4)$ & \\
\hline ASA PS classification & & & 0.160 \\
\hline I & $20(40.8)$ & $38(49.4)$ & \\
\hline$\|$ & $18(36.7)$ & $29(37.7)$ & \\
\hline III & $8(16.3)$ & $10(13.0)$ & \\
\hline IV & $3(6.1)$ & $0(0)$ & \\
\hline TNM stage & & & 0.327 \\
\hline । & $0(0)$ & $0(0)$ & \\
\hline$\|$ & $12(24.5)$ & $28(36.4)$ & \\
\hline III & $21(42.9)$ & $31(40.2)$ & \\
\hline IV & $16(32.6)$ & $18(23.4)$ & \\
\hline Lymphovascular invasion & $26(53.1)$ & $39(50.6)$ & 0.792 \\
\hline Perineural invasion & $13(26.5)$ & $13(16.9)$ & 0.192 \\
\hline Tumor location & & & 0.092 \\
\hline Splenic flexure & $0(0)$ & $7(9.1)$ & \\
\hline Descending colon & $8(16.3)$ & $8(10.4)$ & \\
\hline Sigmoid colon & $21(42.9)$ & $26(33.8)$ & \\
\hline Rectosigmoid colon & $20(40.8)$ & $36(46.8)$ & \\
\hline Follow-up (mo) & $57 \pm 39.6$ & $67 \pm 44.6$ & 0.225 \\
\hline Chemotherapy & $35 / 49(71.4)$ & $48 / 77(62.3)$ & 0.196 \\
\hline Chemotherapy regimen & & & $0.025^{*}$ \\
\hline 5-Fluorouracil-based & $20(57.1)$ & $40(83.3)$ & \\
\hline Oxaliplatin-based & $13(37.1)$ & $8(16.7)$ & \\
\hline Antiangiogenic drug & $2(5.8)$ & $0(0)$ & \\
\hline Radical metastasectomy at 1 year for stage IV disease & $9 / 16(56.3)$ & $14 / 18(77.8)$ & 0.274 \\
\hline
\end{tabular}

Values are presented as number only, mean \pm standard deviation, or number (\%).

SEMS, self-expandable metal stent; ASA, American Society of Anesthesiologists; PS, physical status.

${ }^{*} \mathrm{P}<0.05$.

\section{Secondary outcomes}

Table 3 shows the perioperative outcomes of both groups. In the SEMS group, the technical success rate was $100 \%$, and the clinical success rate was 95.9\%. Patients who did not improve after SEMS insertion underwent emergency surgery. The median interval to surgery after SEMS placement was 15 days (IQR, 8-29 days).

Patients in the SEMS group were more likely to undergo laparoscopic surgery than those in the emergency surgery group (51\% vs. $9 \%, \mathrm{P}<0.001)$. The SEMS group had a higher rate of primary anastomosis without stoma ( $71 \%$ vs. $52 \%, \mathrm{P}=0.03$ ), and a lower permanent stoma rate $(8 \%$ vs. $25 \%, \mathrm{P}=0.02)$ than the emergency surgery group. The temporary stoma rate did not differ between the 2 groups $(\mathrm{P}=0.70)$.

One of the 49 patients $(2.0 \%)$ in the SEMS group had SEMS-related perforation that necessitated emergency colectomy. One patient $(2.0 \%)$ had stent migration 10 days after insertion and underwent emergency colectomy due to symptoms of obstruction. Postsurgical complication rates were not significantly different between the 2 groups ( $29 \%$ vs. $44 \%, \mathrm{P}=0.08$ ). All postoperative complications were categorized using the Clavien-Dindo classification, and we found no difference in their incidence in all grades. The median length of stay after surgery was shorter in the SEMS 


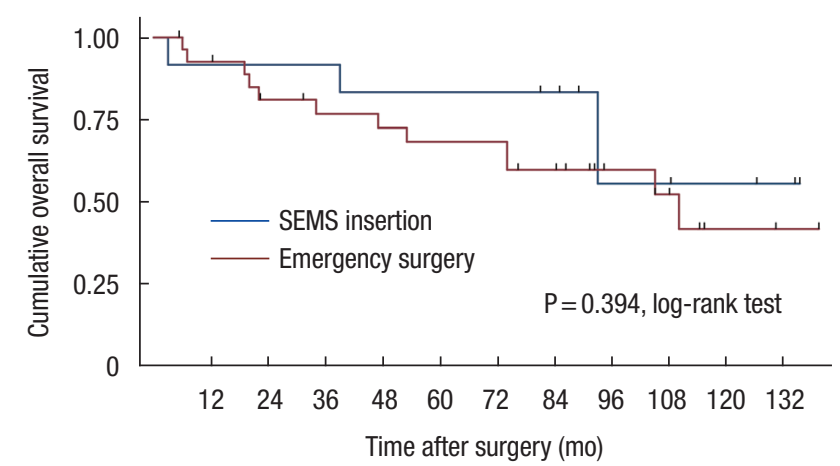

Number at risk

$\begin{array}{lllllllllllll}\text { Stent2 } & 12 & 11 & 11 & 11 & 10 & 10 & 10 & 8 & 4 & 4 & 3 & 2\end{array}$

$\begin{array}{lllllllllllll}\text { Sx2 } & 28 & 25 & 20 & 18 & 17 & 16 & 16 & 13 & 8 & 6 & 2 & 1\end{array}$

Fig. 2. Kaplan-Meier probability of overall survival of patients with stage II malignant obstruction. SEMS, self-expandable metal stent.

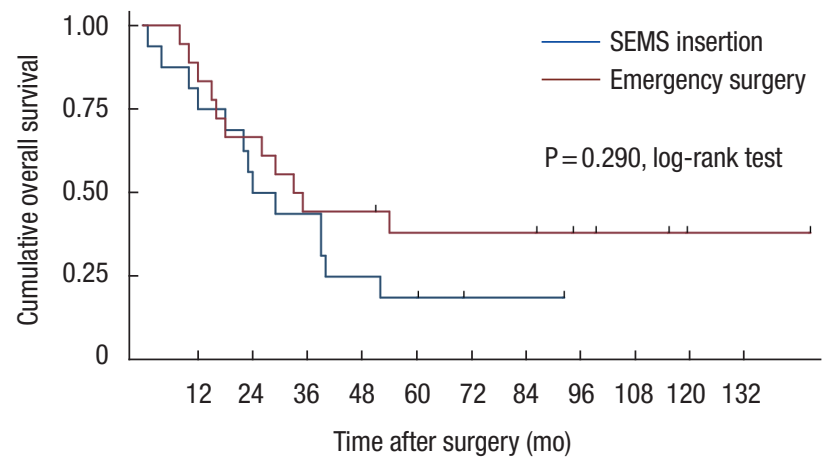

Number at risk

$\begin{array}{lllllllllllll}\text { Stent4 } & 16 & 13 & 9 & 7 & 4 & 3 & 1 & 1 & 0 & 0 & 0 & 0\end{array}$

$\begin{array}{lllllllllllll}\mathrm{S} \times 4 & 18 & 16 & 12 & 8 & 8 & 6 & 6 & 6 & 4 & 3 & 1 & 1\end{array}$

Fig. 3. Kaplan-Meier probability of overall survival of patients with stage IV malignant obstruction. SEMS, self-expandable metal stent.

group ( 8 days vs. 13 days, $\mathrm{P}=0.01$ ) than in the emergency surgery group. No patient died within 30 days of admission.

Multivariate analyses showed that age of $\geq 65$ years, American Joint Committee on Cancer stage of $\geq \mathrm{III}$, and synchronous metastasis were associated with poor OS, while adjuvant chemotherapy was associated with improved OS (Table 4). The type of intervention (SEMS insertion vs. emergency surgery) was not a prognostic factor for OS $(\mathrm{P}=0.47)$.

\section{DISCUSSION}

We found that SEMS as a bridge to surgery may have adverse oncologic outcomes for patients with LMCO compared with emergency surgery. Patients in the SEMS group had a trend of worsening 5-year OS rate without higher recurrence. With regard to short-term outcomes, SEMS as a bridge to surgery had a higher

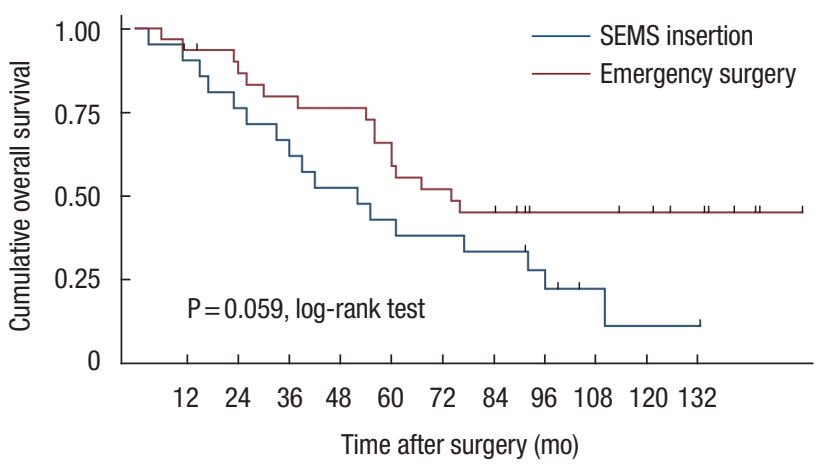

Number at risk

$\begin{array}{lllllllllllll}\text { Stent3 } & 21 & 19 & 16 & 14 & 11 & 9 & 8 & 7 & 5 & 2 & 1 & 1\end{array}$

$\begin{array}{lllllllllllll}\text { Sx3 } & 31 & 28 & 26 & 23 & 22 & 19 & 15 & 13 & 9 & 9 & 8 & 6\end{array}$

Fig. 4. Kaplan-Meier probability of overall survival of patients with stage III malignant obstruction. SEMS, self-expandable metal stent.

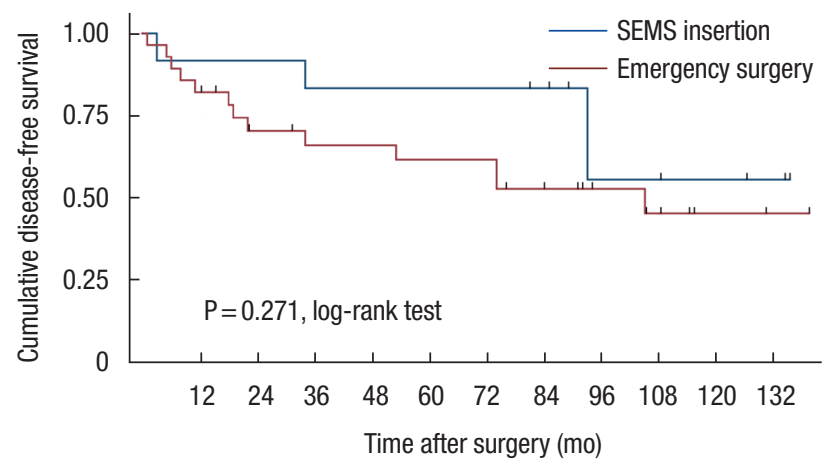

Number at risk

$\begin{array}{rrrrrrrrrrrr}\text { Stent2 } & 11 & 11 & 10 & 10 & 10 & 10 & 8 & 4 & 4 & 3 & 2 \\ \text { Sx2 } & 23 & 17 & 15 & 15 & 14 & 14 & 11 & 7 & 5 & 2 & 1\end{array}$

Fig. 5. Kaplan-Meier probability of disease-free survival of patients with stage II malignant obstruction. SEMS, self-expandable metal stent.

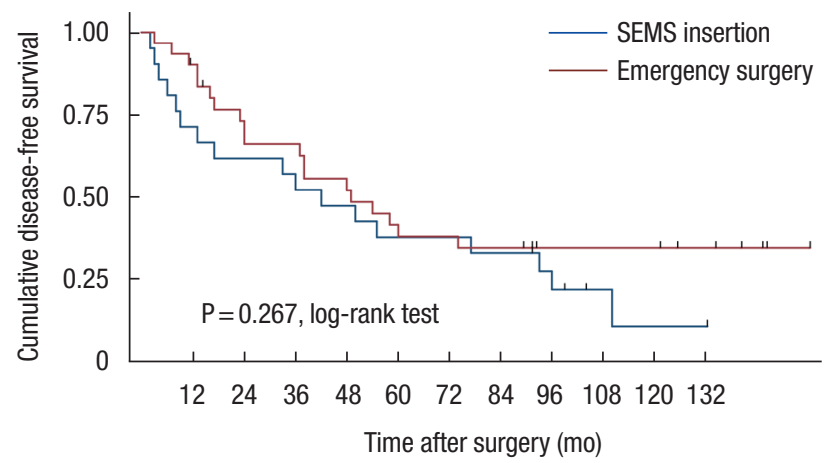

Number at risk

$\begin{array}{rllllccccccc}\text { Stent3 } & 15 & 13 & 12 & 10 & 8 & 8 & 7 & 5 & 2 & 1 & 1 \\ \text { Sx3 } & 27 & 21 & 19 & 16 & 12 & 11 & 10 & 7 & 7 & 7 & 5\end{array}$

Fig. 6. Kaplan-Meier probability of disease-free survival of patients with stage III malignant obstruction. SEMS, self-expandable metal stent. 
Table 2. Rate and pattern of recurrence in the overall population and patients without metastases at the time of diagnosis

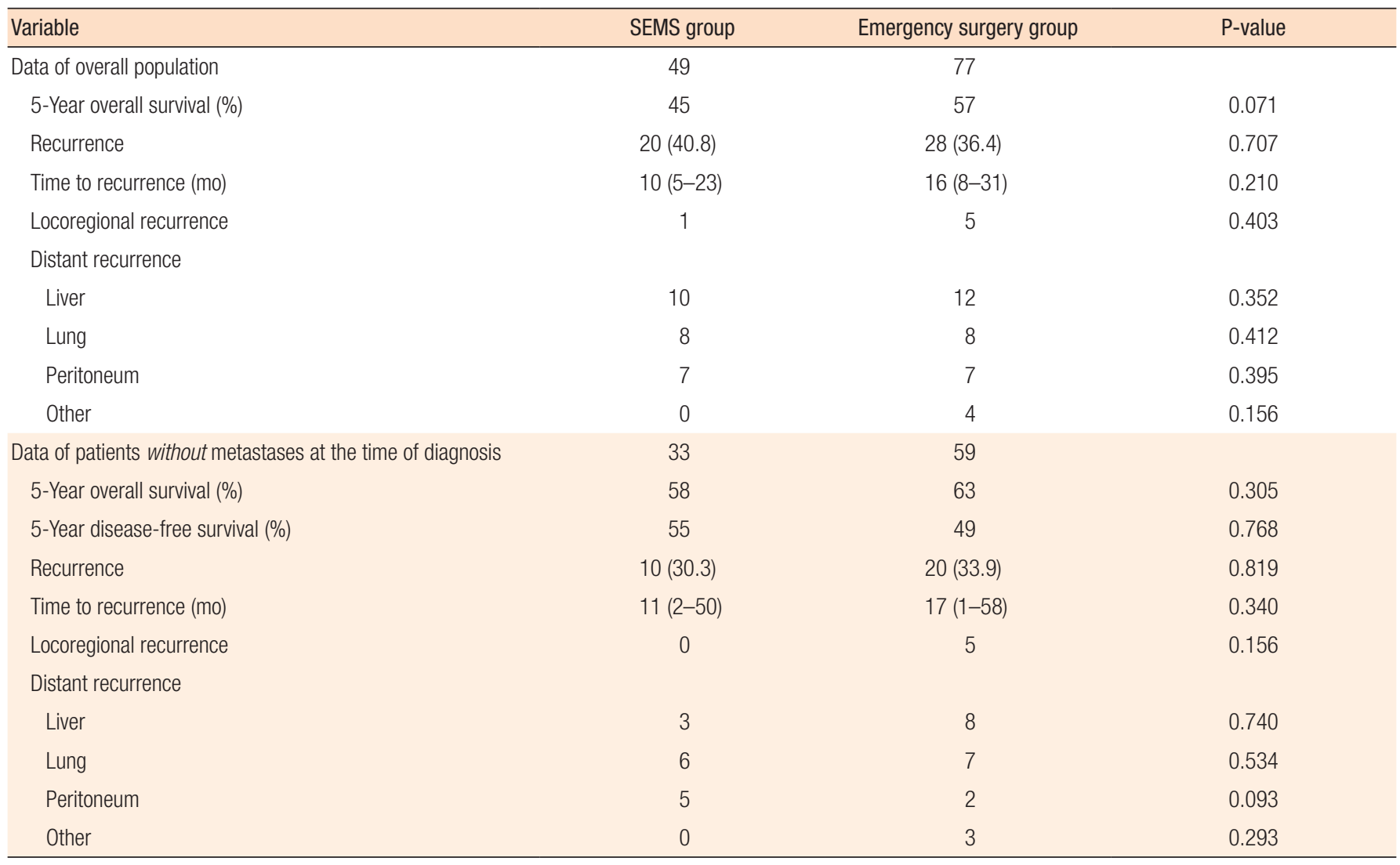

Values are presented as number, percentage, number (\%), or median (interquartile range).

SEMS, self-expandable metal stent.

rate of primary anastomosis without stoma and a lower risk of permanent stoma creation.

The role of SEMS as a bridge to surgery has been debated because of concerns of negative oncologic outcomes. SEMS-related perforation has been found to impair oncologic outcomes [25]. In the Dutch Stent-in 2 trial, Sloothaak et al. [14] found that 5 out of 6 patients with perforation experience recurrence. Moreover, Gorissen et al. [15] reported that local recurrence was more common in patients who underwent SEMS insertion than in those who underwent emergency surgery ( $32 \%$ vs. $8 \%, \mathrm{P}=0.04)$. The perforation rate was $8 \%$, and all patients with perforation experienced recurrence. Sensitivity analyses showed that 3-year OS was significantly better in studies with perforation rates of $<8 \%$ than in those with perforation rates of $\geq 8 \%$ [26]. Several studies that reported low perforation rates showed comparable oncologic outcomes between SEMS as a bridge to surgery and emergency surgery $[7,17,27,28]$. In the present study, $2 \%$ of patients experienced SEMS-related perforation that needed emergency resection. The OS rate of the patients in the SEMS group tended to be poorer than that in the emergency surgery group. By contrast, the DFS and the recurrence rates were not different. However, there were 2 major confounders of survival analysis in this study. The patients in SEMS group were older and more likely to receive the oxaliplatin-based chemotherapy with or without antiangiogenic drug. Thus, we cannot conclude from our results that SEMS insertion does not adversely affect the oncologic outcomes.

SEMS insertion may impair oncologic outcomes even in the absence of perforation. The SEMS can induce shear forces on the tumor, which can lead to the dissemination of cancer cells into the peritoneal cavity, lymphatic fluid, and bloodstream [29]. Maruthachalam et al. [12] observed a more significant increase in cytokeratin 20 messenger RNA expression in peripheral blood after SEMS insertion than after staging colonoscopy. Kim et al. [30] found that the perineural invasion rate, but not the survival rate, increased after SEMS insertion. Moreover, Yamashita et al. [13] reported tumor cell dissemination into peripheral circulation after SEMS insertion. Our study demonstrated a decreasing trend in the OS rate for SEMS as a bridge to surgery, although we observed a low perforation rate. However, it was difficult to ascertain whether tumor dissemination caused impaired OS in the SEMS group because both locoregional and distant recurrence were not higher. To date, although evidence of dissemination of tumor cells during SEMS insertion exists, there is insufficient evidence of its adverse effects on long-term survival and prognosis. 
Table 3. Perioperative outcomes of the SEMS and emergency surgery groups

\begin{tabular}{|c|c|c|c|}
\hline Variable & SEMS group $(n=49)$ & Emergency surgery group $(n=77)$ & P-value \\
\hline Technical success rate & $49(100)$ & NA & \\
\hline Clinical success rate & $47(95.9)$ & NA & \\
\hline Time to surgery (day) & $15(8-29)$ & NA & \\
\hline Type of surgery & & & $<0.001^{\star}$ \\
\hline Open & $24(49.0)$ & $70(90.9)$ & \\
\hline Laparoscopic & $25(51.0)$ & $7(9.1)$ & \\
\hline Primary anastomosis without stoma & $35(71.4)$ & $40(51.9)$ & $0.030^{*}$ \\
\hline \multicolumn{4}{|l|}{ Stoma } \\
\hline Temporary & $10(20.4)$ & $18(23.4)$ & 0.696 \\
\hline Permanent & $4(8.2)$ & $19(24.7)$ & $0.019^{*}$ \\
\hline \multicolumn{4}{|l|}{ Stent complication } \\
\hline Perforation & $1(2)$ & NA & \\
\hline Migration & $1(2)$ & NA & \\
\hline Overall postoperative complication rate & $14(28.6)$ & $34(44.2)$ & 0.079 \\
\hline \multicolumn{4}{|l|}{ Surgical complication (Clavien-Dindo classification) } \\
\hline Grade I & 7 & 17 & 0.659 \\
\hline Grade II & 1 & 7 & 0.149 \\
\hline Grade IIla & 0 & 4 & 0.156 \\
\hline Grade IIIb & 3 & 5 & 0.999 \\
\hline Grade IVa & 1 & 1 & 0.628 \\
\hline \multicolumn{4}{|l|}{ Type of surgical complication } \\
\hline Anastomotic leakage & $3(6.1)$ & $3(3.9)$ & \\
\hline Surgical site infection & $5(10.2)$ & $13(16.9)$ & \\
\hline Small bowel obstruction & $2(4.1)$ & $1(1.3)$ & \\
\hline lleus & $1(2.0)$ & $5(6.5)$ & \\
\hline Ureteric injury & $1(2.0)$ & $1(1.3)$ & \\
\hline Pancreatic fistula & $0(0)$ & $1(1.3)$ & \\
\hline Intraabdominal bleeding & $0(0)$ & $2(2.6)$ & \\
\hline Fluid collection & $0(0)$ & $5(6.5)$ & \\
\hline Chyle leakage & $1(2.0)$ & $1(1.3)$ & \\
\hline Central line-associated infection & $1(2.0)$ & $0(0)$ & \\
\hline Myocardial infarction & $1(2.0)$ & $0(0)$ & \\
\hline Stroke & $0(0)$ & $1(1.3)$ & \\
\hline Pneumonia & $0(0)$ & $2(2.6)$ & \\
\hline Lung atelectasis & $0(0)$ & $1(1.3)$ & \\
\hline Urinary tract infection & $0(0)$ & $1(1.3)$ & \\
\hline Acute urinary retention & $0(0)$ & $3(3.9)$ & \\
\hline Postoperative duration of hospitalization (day) & $8(6-15)$ & $13(9-22)$ & $0.011^{*}$ \\
\hline
\end{tabular}

Values are presented as number (\%), median (interquartile range), or mean \pm standard deviation.

SEMS, self-expandable metal stent; NA, not applicable.

${ }^{*} \mathrm{P}<0.05$.

We demonstrated that SEMS insertion has high technical and clinical success rates (100\% and $95.9 \%$, respectively), with a $2 \%$ chance of SEMS-related perforation. Consequently, we obtained favorable short-term outcomes with low permanent stoma rates and high rates of primary anastomosis without stoma. Moreover, patients in the SEMS group tended to have lower rates of postop- 
Table 4. Factors associated with overall survival in the overall population on univariate and multivariate analyses

\begin{tabular}{|c|c|c|c|c|}
\hline \multirow{2}{*}{ Variable } & \multicolumn{2}{|c|}{ Univariate analysis } & \multicolumn{2}{|c|}{ Multivariate analysis } \\
\hline & $\mathrm{HR}(95 \% \mathrm{Cl})$ & P-value & $\mathrm{HR}(95 \% \mathrm{Cl})$ & P-value \\
\hline Age, $\geq 65$ yr vs. $<65$ yr & $1.973(1.230-3.165)$ & $0.005^{\star}$ & $1.709(1.007-2.900)$ & $0.047^{*}$ \\
\hline ASA PS classification, $\geq$ III vs. <III & $1.518(0.881-2.616)$ & 0.133 & $1.210(0.660-2.220)$ & 0.538 \\
\hline AJCC stage, $\geq$ III vs. $<$ III & $2.051(1.176-3.579)$ & $0.007^{\star}$ & $1.988(1.038-3.809)$ & $0.038^{*}$ \\
\hline Synchronous metastasis, yes vs. no & $2.032(1.240-3.329)$ & $0.005^{\star}$ & $2.146(1.191-3.866)$ & $0.011^{*}$ \\
\hline Adjuvant chemotherapy, yes vs. no & $0.634(0.395-1.017)$ & 0.059 & $0.536(0.314-0.914)$ & $0.022^{*}$ \\
\hline Surgical technique, MIS vs. open & $1.498(0.913-2.456)$ & 0.110 & $1.483(0.805-2.733)$ & 0.206 \\
\hline Type of surgery, SEMS vs. ES & $1.521(0.959-2.412)$ & 0.075 & $1.233(0.701-2.170)$ & 0.467 \\
\hline
\end{tabular}

HR, hazard ratio; Cl, confidence interval; ASA, American Society of Anesthesiologists; PS, physical status; AJCC, American Joint Committee on Cancer; MIS, minimally invasive surgery; SEMS, self-expandable metal stent; ES, emergency surgery.

${ }^{*} \mathrm{P}<0.05$.

erative complications than those in the emergency surgery group ( $29 \%$ vs. $44 \%, \mathrm{P}=0.08$ ). To improve the short-term outcome of SEMS insertion, the technical and clinical failure rates should be minimized. In a previous study, Cheung et al. [8] reported high technical and clinical success rates (100\% and $83 \%$, respectively) with no incidence of perforation. Patients in the SEMS group had significantly lower morbidity than those in the emergency surgery group ( $8 \%$ vs. $70 \%$, respectively). In a multicenter randomized trial, van Hooft et al. [31] reported a technical success rate of $70 \%$, clinical success rate of $70 \%$, and perforation rate of $12.7 \%$. Morbidity tended to be higher in the SEMS group than in the emergency surgery group ( $53 \%$ vs. $45 \%, \mathrm{P}=0.43$ ). Thus, high success rates and low perforation rates are key factors for obtaining promising short-term outcomes following SEMS insertion.

In 2014, the European Society of Gastrointestinal Endoscopy (ESGE) guidelines did not recommend using SEMS as a bridge to surgery based on studies with low success rates and high complication rates [32]. However, many comparative studies and 1 randomized controlled trial were subsequently published. They reported high success rates and good oncologic outcomes [17-23]. Considering this, the updated ESGE guidelines released in 2020 consider SEMS insertion as a bridge to surgery as a valid treatment option in patients with LMCO. However, the risk and benefit of SEMS insertion should be discussed by the medical team. Furthermore, they underlined that SEMS insertion should be performed or directly supervised by a competent endoscopist [33].

Our study has several limitations. First, since this was a retrospective cohort study, selection bias by the consultant colorectal surgeon occurred regarding treatment choice. Older adults with comorbidities were more likely to undergo SEMS insertion as a bridge to surgery than emergency surgery. Therefore, the OS rate was confounded by the difference in age between the groups. Besides, we could not avoid the impact of the patients' financial status and medical reimbursement on treatment selection. Patients with the Civil Servant Medical Benefit Scheme were more likely to receive SEMS insertion and oxaliplatin-based chemotherapy with or without antiangiogenic drug. The results of this study are difficult to verify because of these major confounders. Second, emergency surgery encompasses various procedures (Hartmann procedure, segmental colectomy with/without on-table lavage, subtotal/total colectomy). Each procedure has advantages and disadvantages that might affect the outcome. However, there is no clear evidence favoring 1 procedure over another. Finally, the sample size was small because this was a single-center study. This might be the reason for the differences in the OS rate not being statistically significant. However, it is easier to standardize the SEMS insertion technique in a single-center study than in a multicenter study. This might have contributed to the high success rate of SEMS insertion in our study.

SEMS as a bridge to surgery may have adverse oncologic outcomes. Patients in the SEMS group showed a trend of worsening 5 -year OS rate without higher recurrence. However, the patients that underwent SEMS as a bridge to surgery were older and more likely to receive the oxaliplatin-based chemotherapy with or without antiangiogenic drug than those who underwent emergency surgery. These factors may have confounded the outcomes of this study. Therefore, further studies are needed to investigate the role of SEMS as a bridge to surgery.

\section{CONFLICT OF INTEREST}

No potential conflict of interest relevant to this article was reported.

\section{FUNDING}

None.

\section{REFERENCES}

1. Bray F, Ferlay J, Soerjomataram I, Siegel RL, Torre LA, Jemal A. 
Global cancer statistics 2018: GLOBOCAN estimates of incidence and mortality worldwide for 36 cancers in 185 countries. CA Cancer J Clin 2018;68:394-424.

2. Cao Y, Gu J, Deng S, Li J, Wu K, Cai K. Long-term tumour outcomes of self-expanding metal stents as 'bridge to surgery' for the treatment of colorectal cancer with malignant obstruction: a systematic review and meta-analysis. Int J Colorectal Dis 2019;34: 1827-38.

3. Fielding LP, Phillips RK, Hittinger R. Factors influencing mortality after curative resection for large bowel cancer in elderly patients. Lancet 1989;1:595-7.

4. Tekkis PP, Kinsman R, Thompson MR, Stamatakis JD; Association of Coloproctology of Great Britain, Ireland. The Association of Coloproctology of Great Britain and Ireland study of large bowel obstruction caused by colorectal cancer. Ann Surg 2004;240:7681.

5. Tanis PJ, Paulino Pereira NR, van Hooft JE, Consten EC, Bemelman WA; Dutch Surgical Colorectal Audit. Resection of obstructive left-sided colon cancer at a national level: a prospective analysis of short-term outcomes in 1,816 patients. Dig Surg 2015;32: 317-24.

6. Mulcahy HE, Skelly MM, Husain A, O’Donoghue DP. Long-term outcome following curative surgery for malignant large bowel obstruction. Br J Surg 1996;83:46-50.

7. Alcántara M, Serra-Aracil X, Falcó J, Mora L, Bombardó J, Navarro S. Prospective, controlled, randomized study of intraoperative colonic lavage versus stent placement in obstructive left-sided colonic cancer. World J Surg 2011;35:1904-10.

8. Cheung HY, Chung CC, Tsang WW, Wong JC, Yau KK, Li MK. Endolaparoscopic approach vs conventional open surgery in the treatment of obstructing left-sided colon cancer: a randomized controlled trial. Arch Surg 2009;144:1127-32.

9. Ghazal AH, El-Shazly WG, Bessa SS, El-Riwini MT, Hussein AM. Colonic endolumenal stenting devices and elective surgery versus emergency subtotal/total colectomy in the management of malignant obstructed left colon carcinoma. J Gastrointest Surg 2013;17: 1123-9.

10. Ho KS, Quah HM, Lim JF, Tang CL, Eu KW. Endoscopic stenting and elective surgery versus emergency surgery for left-sided malignant colonic obstruction: a prospective randomized trial. Int J Colorectal Dis 2012;27:355-62.

11. Pirlet IA, Slim K, Kwiatkowski F, Michot F, Millat BL. Emergency preoperative stenting versus surgery for acute left-sided malignant colonic obstruction: a multicenter randomized controlled trial. Surg Endosc 2011;25:1814-21.

12. Maruthachalam K, Lash GE, Shenton BK, Horgan AF. Tumour cell dissemination following endoscopic stent insertion. Br J Surg 2007;94:1151-4.

13. Yamashita S, Tanemura M, Sawada G, Moon J, Shimizu Y, Yamaguchi $\mathrm{T}$, et al. Impact of endoscopic stent insertion on detection of viable circulating tumor cells from obstructive colorectal cancer. Oncol Lett 2018;15:400-6.
14. Sloothaak DA, van den Berg MW, Dijkgraaf MG, Fockens P, Tanis PJ, van Hooft JE, et al. Oncological outcome of malignant colonic obstruction in the Dutch Stent-In 2 trial. Br J Surg 2014;101: 1751-7.

15. Gorissen KJ, Tuynman JB, Fryer E, Wang L, Uberoi R, Jones OM, et al. Local recurrence after stenting for obstructing left-sided colonic cancer. Br J Surg 2013;100:1805-9.

16. Katsuki R, Jo T, Yasunaga H, Ishimaru M, Sakamoto T. Outcomes of self-expandable metal stent as bridge to surgery versus emergency surgery for left-sided obstructing colon cancer: a retrospective cohort study. Am J Surg 2021;221:168-73.

17. Yang SY, Park YY, Han YD, Cho MS, Hur H, Min BS, et al. Oncologic outcomes of self-expandable metallic stent as a bridge to surgery and safety and feasibility of minimally invasive surgery for acute malignant colonic obstruction. Ann Surg Oncol 2019;26: 2787-96.

18. Saito S, Yoshida S, Isayama H, Matsuzawa T, Kuwai T, Maetani I, et al. A prospective multicenter study on self-expandable metallic stents as a bridge to surgery for malignant colorectal obstruction in Japan: efficacy and safety in 312 patients. Surg Endosc 2016;30: 3976-86.

19. Arezzo A, Balague C, Targarona E, Borghi F, Giraudo G, Ghezzo L, et al. Colonic stenting as a bridge to surgery versus emergency surgery for malignant colonic obstruction: results of a multicentre randomised controlled trial (ESCO trial). Surg Endosc 2017; 31:3297-305.

20. Amelung FJ, Borstlap WA, Consten EC, Veld JV, van Halsema EE, Bemelman WA, et al. Propensity score-matched analysis of oncological outcome between stent as bridge to surgery and emergency resection in patients with malignant left-sided colonic obstruction. Br J Surg 2019;106:1075-86.

21. Lara-Romero C, Vilches Á, Caunedo-Álvarez Á, Hergueta-Delgado P, Lavín-Castejón I, Andrade-Bellido R, et al. Better recurrence-free survival after stent bridge to surgery compared to emergency surgery for obstructive left-sided colonic cancer in patients with stage III status of the American Joint Committee on Cancer (AJCC): a bicentric retrospective study. Int J Colorectal Dis 2019;34:1241-50.

22. Kang SI, Oh HK, Yoo JS, Ahn S, Kim MH, Kim MJ, et al. Oncologic outcomes of preoperative stent insertion first versus immediate surgery for obstructing left-sided colorectal cancer. Surg Oncol 2018;27:216-24.

23. Park J, Lee HJ, Park SJ, Hur H, Min BS, Cheon JH, et al. Longterm outcomes after stenting as a bridge to surgery in patients with obstructing left-sided colorectal cancer. Int J Colorectal Dis 2018;33:799-807.

24. Dindo D, Demartines N, Clavien PA. Classification of surgical complications: a new proposal with evaluation in a cohort of 6336 patients and results of a survey. Ann Surg 2004;240:205-13.

25. Balciscueta I, Balciscueta Z, Uribe N, García-Granero E. Longterm outcomes of stent-related perforation in malignant colon obstruction: a systematic review and meta-analysis. Int J Colorectal 
Dis 2020;35:1439-51.

26. Amelung FJ, Burghgraef TA, Tanis PJ, van Hooft JE, Ter Borg F, Siersema PD, et al. Critical appraisal of oncological safety of stent as ridge to surgery in left-sided obstructing colon cancer; a systematic review and meta-analysis. Crit Rev Oncol Hematol 2018;131:66-75.

27. Tung KL, Cheung HY, Ng LW, Chung CC, Li MK. Endo-laparoscopic approach versus conventional open surgery in the treatment of obstructing left-sided colon cancer: long-term follow-up of a randomized trial. Asian J Endosc Surg 2013;6:78-81.

28. Endo S, Kumamoto K, Enomoto T, Koizumi K, Kato H, Saida Y. Comparison of survival and perioperative outcome of the colonic stent and the transanal decompression tube placement and emergency surgery for left-sided obstructive colorectal cancer: a retrospective multi-center observational study "The CODOMO study". Int J Colorectal Dis 2021;36:987-98.

29. Matsuda A, Miyashita M, Matsumoto S, Matsutani T, Sakurazawa $\mathrm{N}$, Takahashi G, et al. Comparison of long-term outcomes of colonic stent as "bridge to surgery" and emergency surgery for malignant large-bowel obstruction: a meta-analysis. Ann Surg Oncol
2015;22:497-504.

30. Kim HJ, Choi GS, Park JS, Park SY, Jun SH. Higher rate of perineural invasion in stent-laparoscopic approach in comparison to emergent open resection for obstructing left-sided colon cancer. Int J Colorectal Dis 2013;28:407-14.

31. van Hooft JE, Bemelman WA, Oldenburg B, Marinelli AW, Lutke Holzik MF, Grubben MJ, et al. Colonic stenting versus emergency surgery for acute left-sided malignant colonic obstruction: a multicentre randomised trial. Lancet Oncol 2011;12:344-52.

32. van Hooft JE, van Halsema EE, Vanbiervliet G, Beets-Tan RG, DeWitt JM, Donnellan F, et al. Self-expandable metal stents for obstructing colonic and extracolonic cancer: European Society of Gastrointestinal Endoscopy (ESGE) Clinical Guideline. Endoscopy 2014;46:990-1053.

33. van Hooft JE, Veld JV, Arnold D, Beets-Tan RG, Everett S, Götz M, et al. Self-expandable metal stents for obstructing colonic and extracolonic cancer: European Society of Gastrointestinal Endoscopy (ESGE) Guideline: update 2020. Endoscopy 2020;52:389-407. 